\title{
A política florestal e o futuro promissor da fruticultura na Amazônia
}

\author{
Charles Roland Clement * \\ David Bradwell Arkcoll*
}

Nos trópicos úmidos do mundo, algumas das culturas mais importantes são frutícolas, como cacau, castanha-do-Pará, dendê e banana, todas as quais têm mercados mundiais extensivos. Essas culturas também estão geralmente fadadas a ser ecológicamente satisfatórias dada a sua similaridade à estrutura da floresta. Seus potenciais foram aproveitados após seleção considerável, pelos indígenas e pelos pesquisadores, para desenvolver e fixar as características econômicas mais desejáveis. E essa seleção está continuando hoje como a procura de variabilidade genética de cacau, dendê (caiaué na Amazônia) e castanha-doPará que ainda pode ser encontrada na Amazônia, o maior repositório mundial de recursos genéticos frutícolas. Inúmeras outras fruteiras amazônicas poderiam ter um potencial econômico similar, desde que os esforços científicos necessários fossem aplicados. Então a política florestal deve impedir qualquer redução desse repositório genético evitando assim diminuir o potencial futuro para a fruticultura, um dos sistemas mais apropriados para a região amazônica.

\section{DIVERSIDADE GENÉTICA DAS ESPÉCIES FRUTÍFERAS NA AMAZÔNIA}

É óbvio, que o desmatamento em grande escala pode extinguir uma espécie completa ou maiores ou menores partes da diversidade genética de uma espécie. A redução da diversidade de uma espécie é muito mais importante do que normalmente se pensa porque é aqui que se procuram as características de interesse econômico para o melhoramento da espécie, que possibilitam o aproveitamento do seu potencial. Uma idéia da importância da diversidade genética encontrada nas populações locais pode ser obtida considerando o caso da pupunha (Bactris gasipaes H.B.K.), uma palmeira amazônica que achamos ter potencial econômico na produção de fruto, pal- mito, óleo e farinha, dependendo da preferência de seleção. A variabilidade genética dessa espécie inclui: forma da copa, área e distribuição das folhas, diâmetro do tronco, troncos com e sem espinhos, árvores anãs, número de cachos/árvore, número de frutos/cacho, tamanho e forma do fruto, peso do cacho, partenocarpia, autofertilidade, \% polpa/fruto, sabor, conteúdos de proteína, óleo e fibra, resistência a pragas e doenças, precocidade e produção contínua, com essas características encontradas a diferentes níveis em diferentes populações genéticas locais.

Disto conclui-se, que a extinção de populações genéticas locais é de extrema importância, representa uma grande preocupação para os geneticistas e agrônomos do país e do mundo porque, uma vez extinta ou degradada, perdem-se completamente milhares de genes de potencial econômico desconhecido que apareceram durante milhares de anos de evolução.

Além disso, o desaparecimento de uma parte da diversidade genética é mais rápido e fácil do que a eliminação da espécie como um todo, porque uma determinada característica pode ser muito localizada. A perda dessa diversidade parece ser proporcional à área desmatada e, então, reservas biológicas que podem proteger a espécie não vão preservar toda a diversidade que muitas vezes é essencial para a introdução de novas culturas indígenas. A diversidade, e sua loccalização, de espécies com expressão econômica e as consideradas promissoras deveriam ser cuidadosamente tratadas pelos responsáveis pelo planejamento de parques nacionais e áreas de desenvolvimento prioritário.

Entretanto, a melhor solução é aumentar os esforços para identificar, coletar e selecionar tudo o que for possível da diversidade genética das espécies com qualquer potencial econômico, para estudar-se e aproveitar a riqueza amazônica. Essa coleção de material

* Instituto Nacional de Pesquisas da Amazônia, Manaus - AM 
genético deveria ser feita o mais breve possível por causa do rítmo acelerado do desmatamento atual, especialmente em certas áreas de cơlonização.

Por enquanto, está sendo feito pouco para identificar, coletar e conservar esse patrimô. nio genético vegetal antes de seu desaparecimento. Pelo contrário, muitas vezes, como por exemplo, na exploração madeireira, somente as árvores com melhor forma, e portanto melhor patrimônio genético, são retiradas, degradando seriamente as demais populações (MagaIhães et al. na presente publicação]. Além disto, os colonizadores e desmatadores que vêem de outras regiões do país e do mundo ignoram os frutos locais, permitindo sua destruição sem saber o que estão fazendo.

Atualmente, somente um pequeno número de pesquisadores e amadores trabalham na vasta região amazồnica, tentando identificar, conservar e estudar essa enorme diversidade genética a fím de desenvolver novas variedades ou produtos frutícolas para a região e o pais. Poucos botânicos regionais mostraram grande interesse nas características econômicas das espécies indígenas, que têm uma reflexão nos trabalhos publicados. Observa-se que as principais reterências na botânica econômica regional, estão com uns 30 a 50 anos, como Le Cointe (1947), Pio Correa (1926) e Hoehne (1946).

Assim, uma necessidade urgente que deveria ser associada a qualquer política planejada para a região amazônica seria um levantamento de toda a flora amazônica para identificar, coletar, avaliar e conservar todas as plantas que demonstram qualquer potencial econômico, seja frutífero, seja medicinal, oleaginoso, ou de outro qualquer interesse. Um levantamento desses, por sua natureza, deveria ser o mais multidisciplinar possível, com especial envolvimento dos botânicos econômicos, etnobotânicos e antropólogos, buscando também as plantas mais usadas pelos índios, que são os grandes conhecedores da região. Um esquema lógico para a introdução de plantas indígenas é mostrado no Quadro I.

Calzavara (1978) afirma, sem qualquer exagero retórico, que a região amazônica é o mais vasto repositório de espécies frutíferas do globo, porém a maioria dessa riqueza é pouco conhecida fora das regiões em que ocorrem. O cálculo de Calzavara (1978) mostra que 71 espécies de frutíferas indígenas possuem um bom potencial, além de 19 espécies exóticas que vêm dos trópicos americanos ou asiáticos. Cavalcante (1976) relaciona mais de 120 espécies indígenas e exóticas no seu livro, com mais um volume em preparação. Clement et al. (1978) mencionam 10 espécies de grande potencial, algumas das quais estão começando a receber a atenção da pesquisa.

O Quadro II mostra algumas das espécies interessantes das 3 listas mencionadas cujas diversidades genéticas estão recebendo alguma atenção.

Pode ver-se que o levantamento da flora amazônica para identificar espécies frutíferas está sendo iniciado, inclusive o Projeto Flora do CNPq está registrando informação, porém sabe-se que ainda há muitas espécies e características para serem encontradas. Infelizmente, os próximos passos estão pouco adiantados. A coleção de material genético novo é demorada e cara, necessitando de apoio firme e continuidade na pesquisa que deveria seguílo. A avaliação, obviamente, espera a coleção do material genético.

Vale mencionar que essa diversidade de espécies e variedades frutíferas não é grande somente em número de frutos, mas também nas características importantes em produtos que podem ser processados e desenvolvidos deles, por exemplo, chocolate, óleo de dendê e doces. Assim, precisaria de muito trabalho feito pelos nutricionistas, químicos, tecnólogos de alimentos, etc., para alcançar todo o potencial econômico de cada espécie para os mercados locais ou externos.

\section{VANTAGENS ECONÔMICAS DE CULTURAS FRUTICOLAS PERENES}

No trópico úmido observa-se que as culturas mais importantes são as arbóreas e que a maioria delas são frutícolas. Elas têm essa importância porque os produtos são de alto valor ou são altamente rentáveis.

Essa rentabilidade é devida também ao fato de que as culturas perenes são a longo prazo, de modo que os gastos iniciais com a 
QUADRO I - A introdução e exploração de plantas com potencial econômico para a Amazônia
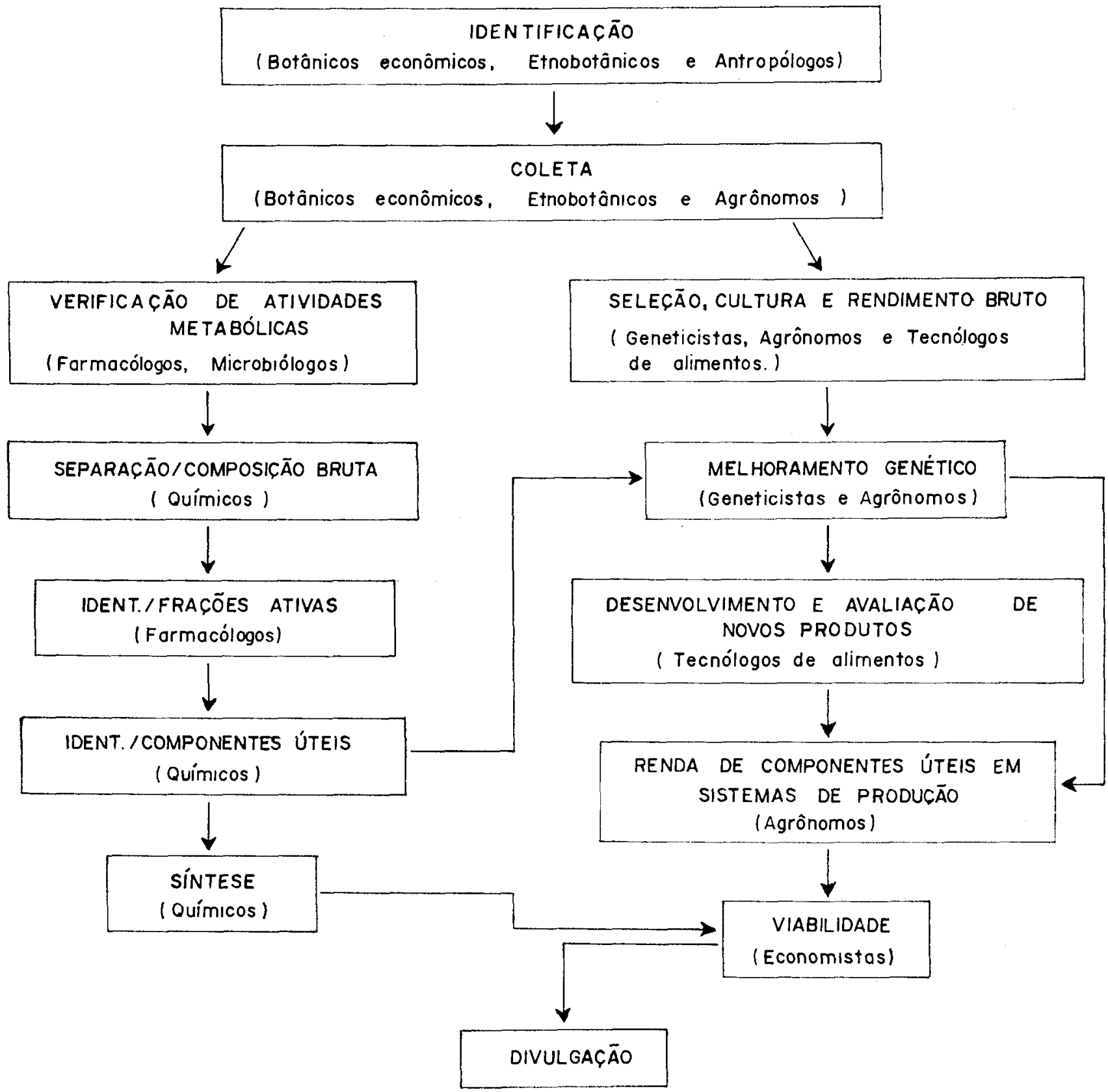

preparação do terreno, adubação fundamental e implantação são amortizados durante muitos anos, pouco a pouco. Também a rentabilidade por área, com culturas frutícolas, é bem maior do que a encontrada com sistemas alternativos, se não for a cultura intensiva de hortaliças.

As culturas perenes frutícolas são altamente eficientes no seu uso de adubos dado o seu sistema radicular extensivo, permanente e altamente eficiente na absorção e ciclagem de nutrientes aplicados (Arkcoll, 1979).

O potencial econômico e a demanda nos mercados regionais, nacionais e mundiais para frutos tropicais estão aumentando continuamente face, em parte, à explosão demográfica regional, nacional e mundial e aos contínuos avançơs na tecnologia de aproveitameno dos produtos frutícolas (Ochse, 1974). De fato, um aumento nesse mercado depende, em gran- 
QUADRO II - Algumas Espécies Frutícolas com Potenclal Econômico

\begin{tabular}{|c|c|c|c|c|}
\hline & Nome vulgar & Nome científico & Família & Us os \\
\hline 1. & Pupunha & Bactris gasipaès & Palmácea & $\begin{array}{l}\text { Fruto cozido p/alimento humano e/ou ani- } \\
\text { mal, palmito, óleo, farinha. }\end{array}$ \\
\hline $\begin{array}{l}2 . \\
3 .\end{array}$ & $\begin{array}{l}\text { Castanha-do-Pará } \\
\text { Cupuaçu }\end{array}$ & $\begin{array}{l}\text { Bertholletia excelsa } \\
\text { Theobroma grandiflorum }\end{array}$ & $\begin{array}{l}\text { Lecitidácea } \\
\text { Sterculiácea }\end{array}$ & $\begin{array}{l}\text { Castanha, óleo, madeira, } \\
\text { Polpa p/suco, doces, compotas, caroços } \\
\text { p/chocolate branco. }\end{array}$ \\
\hline 4. & Bacuri do Pará & Platonia insignis & Gutífera & Polpa p/doces, compotas e sorvetes. \\
\hline 5. & Graviola & Annona muricata & Anonácea & Polpa $\mathrm{p} /$ sucos, sorvetes e em natura \\
\hline 6. & Sapoti & Manilkara zapota & Sapotácea & Polpa $p /$ sucos, sorvetes e em natura \\
\hline 7. & Sapota & Quararibea cordata & Bombacácea & Polpa $p /$ sucos e em natura \\
\hline 8. & Açaí do Pará & Euterpe oleracea & Palmácea & Palmito, polpa $\mathrm{p} / \mathrm{sucos}$ e sorvetes \\
\hline 9. & Araçá boi & Eugenia stipitata & Mirtácea & Polpa $\mathrm{p} /$ sucos, sorvetes e doces \\
\hline 10. & Patauá & Jessenia bataua & Palmácea & Oleo, polpa $\mathrm{p} /$ sucos e sorvetes \\
\hline 11. & Mapati & Pourrouma cecropiaefolia & Morácea & Fruto em natura, sucos e vinhos(?) \\
\hline 12. & Murici & Byrsonima crassifolia & Malpiguiácea & Polpa $\mathrm{p} /$ sucos, sorvetes e doces \\
\hline 13. & Abiu & Pouteria caimito & Sapotácea & Fruta em natura \\
\hline
\end{tabular}

de parte, dos avanços tecnológicos em processamento e empacotamento, os quais permitirão o transporte de frutos ou seus produtos para consumidores distantes.

Especialmente interessante para um futuro muito próximo é o fato da escassez de petróleo, que permitirá, ou melhor, exigirá o desenvolvimento de novos produtos na base de matéria-prima renovável. Já se vêem diversas espécies, como dendê, copaíba e babaçú, sob mira para fornecer matéria-prima para substiuir petróleo na indúsria petroquímica. Dendê, por exemplo, é uma espécie muito eficiente na produção de biomassa utilizável e, sendo sempre renovável, tem um futuro promissor, nesse sentido.

$\mathrm{Na}$ Amazônia de hoje, as vantagens aqui mencionadas são bem conhecidas, pelo menos, pelos técnicos e produtores melhores informados, porém, diversas são as razões que contribuem para uma fruticultura fraca na região. Infraestrutura, ou melhor, sua escassez, é um dos principais fatores, aliada a um mercado regional pouco desenvolvido e exigente. Falta de sementes, orientação técnica, financiamento adequado e pesquisa são as principais falhas regionais. A ausência de transporte e de facilidades para o processamento e armazenamento dos produtos também não permitem aos produtos chegarem aos mercados regionais ou externos onde a demanda pode ser maior. Questões fundiárias também complicam a vida dos agricultores dificultando o planejamento de culturas de longo prazo. Se esses problemas e mais alguns do mesmo gênero forem resolvidos, a fruticultura tropical poderia crescer rapidamente, mesmo sem incentivos governamentais.

\section{VANTAGENS ECOLOGICAS DE CULTURAS FRUTÍCOLAS PERENES}

O principal aspecto ecológico das flores. tas dos trópicos úmidos é sua estabilidade. Por Exemplo a maioria dos nutrientes são ciclados e reciclados dentro do sistema pelo cres. cimento da biomassa, sua morte e decomposição, absorção pelas raízes, então voltando à biomassa e mantendo o sistema em equilíbrio. Assim não é surpreendente, que as culturas tropicais mais importantes são as arbóreas, como seringa e cacau, que efetivamente seguem o modelo florestal.

Talvez o fator mais importante que segue a implantação de culturas perenes, especialmente arbóreas, é a conservação do solo (Alvim, 1978). As copas das plantas protegem o solo da força intensa das chuvas que causam erosão ao mesmo tempo que o sombreia do sol intenso, que protege o solo de endurecimento. Essa conservação é aumentada ainda 
pelo sistema radicular das plantas que impedem a erosão do solo, ao mesmo tempo em que as raízes entram na ciclagem de nutrientes e material orgânico, que é importante na manutenção da capacidade de troca catiônica. O sistema radicular desenvolvido também oferece resistência aos excessos climáticos como secas e enchentes.

Questões sobre o microclima em plantios perenes e seu efeito ao clima local nos trópicos úmidos ainda não estão bem estudados porém, pode-se dizer, que a similaridade entre a floresta e culturas perenes arbóreas, em termos de evapotranspiração, captação e reflexão de energia solar e turbulência atmosférica, são maiores do que entre a floresta e outros sistemas agrícolas.

Doenças são raramente muito graves na floresta natura! tropical, apesar das condições excelentes para doenças nos trópicos úmidos (Arkcoll, 1979). Isto è devido à heterogeneidade da floresta. Atualmente a idéia de duplicar essa heterogeneidade, aproximadamente, nos plantios perenes pela mistura de cultura arbóreas está sendo objeto de atenção. Essa mistura também pode permitir um uso mais completo da energia solar e dos nutrientes devidos à distribuição dos sistemas radiculares e aéreos que exploraram mais completamente seus espaços.

\section{CONCLUSÕES}

1. A fruticultura em qualquer escala, desde o pequeno agricultor até à agroindústria, é uma opção muito apropriada aos trópicos úmidos brasileiros, ecológica e econômicamente.

2. A Amazônia é um repositório enorme de espécies de frutíferas conhecidas e desconhecidas com potencial considerável e, dentro dessas espécies, há muita diversidade genética para ser explorada comercialmente.

3. A perda de espécies e especialmente da sua diversidade genética é quase proporcional à área desmatada. Este fato deveria ser considerado com muito mais atenção pelos planejadores de desenvolvimento. Por exemplo, áreas conhecidas de concentrações da diversidade genética de espécies com expressão econômica, como seringa, cacau, castanha-do-Pará e caiaué, deveriam receber estudos e proteção prioritários.

4. Um levantameno das espécies e sua diversidade genética com potencial econômico e a coleção e avaliação desse material, precisa de muito mais ênfase e deve ser realizado o mais breve possivel, especialmente nas áreas atingidas pelo desenvolvimento.

5. Isso tudo significa que é preciso dar mais ênfase e apoio às pesquisas de botânica econômica e áreas relacicnadas para estudar o potencial econômico do patrimônio genético da Amazônia.

\section{BIBLIOGRAFIA}

Alvim, Paulo de T.

1978 - Floresta Amazônica: equilíbrio entre utilização e conservação. Ciência e Cultura, 30(1) : 9-16.

ARKcoll, David B.

1979 - Nutriente recycling as an alternative to shifting cultivation. Conference on Ecodevelopment and Ecofarming, Berlin, Science Foundation, Alemanha. (no prelo).

Calzavara, Batista B.G.

1978 - A fruticultura como opção econômica para a Amazônia. 1. Encontro Nacional de Fruticultura Tropical, Manaus, AM. (no prelo).

Cavalcante, Paulo B.

1976 - Frutas Comestíveis da Amazônia. INPA, Belém, PA. $166 \mathrm{p}$.

Ciement, Charles R.; Kerr, Warthtck E.; Weber, H.; Freitas JR., Elias de.; Arkcoll, David B.; Ranzani, G. \& Pahlen, Eva van der

1978 - Ecologia e Fruticultura na Amazônia. 1.॰ Encontro Nacional de Fruticultura Tropical, Manaus, AM. (no prelo).

Correa, M. Pio

1926 - Dicionário das Plantas Úteis do Brasil. Min. Agricultura, Rio de Janeiro, RJ, 6 vol.

Hoehne, Frederico C.

1946 - Frutas indígenas, Instituto de Botânica, São Paulo, SP. 87 p.

Le Cointe, Paulo

1947 - Arvores e Plantas Úteis, 2.a Ed. Brasiliana. vol. 251, Série, 5:506 p.

OChSE, J.J.; Soule, JR. M.J.; DiJkmaN, M.J. \& WEHLBURG, C.

1974 - Cultivo y mejoramiento de plantas tropicales y subtropicales, Ed. Limusa, México. $1445 \mathrm{p}$. 